\title{
Article
}

\section{Digital potentiometers and digital-to-analog converters in tasks for tuning of active RC-filters}

\author{
Butyrlagin N. V. ${ }^{1}$, Titov A. E. ${ }^{2}$, Kleimenkin D. V. ${ }^{1}$, Pakhomov I. V. ${ }^{1}$ \\ ${ }^{1}$ Don State Technical University, Rostov-on-Don, Russia \\ ${ }^{2}$ Southern Federal University, Rostov-on-Don, Russia \\ *E-mail: butyrlagin@gmail.com, ORCID: 0000-0002-6363-5113.
}

\begin{abstract}
:
The most popular schemes of digital potentiometers (DP) and digital-to-analog converters (DAC) are considered. DP and DAC use how elements of parameter adjustment of active RC-filters. The circuits of the DAC on the Kelvin-Varley divider, the Kelvin divider based on the R-2R matrix, and the architecture of the DAC with a segmented circuit are shown. The internal structure of DP an Analog Devices and Intersil company is shown, and also the DP switching circuits in a tunable low-pass filter and a band-pass filter, a programmable inverting amplifier and a voltage regulator are presented.
\end{abstract}

Keywords: active RC-filter, digital tuning elements, digital potentiometer, digitalto-analog converter, low-pass filter, band-pass filter, inverting amplifier, voltage regulator.

\section{Introduction}

Active RC-filters (ARCF) are widely used in radio engineering, measuring equipment and automation [1-3]. The implementation of high-precision analog signal conversion in frequency selection devices requires the use of precision elements or calibration procedures using electronic components with controlled characteristics [4-21]. Digital-to-analog converter (DAC) [22-26] or digital potentiometer (DP) [27-38] can be selected as adjustment elements.

The purpose of the article is a brief overview of digital elements for tuning of characteristics in active RC-filters - DAC and DP. 


\section{Digital-to-analog converters}

The DACs in the ARCF are used as controlled signal dividers. Fig. 1 shows two types of segmented DAC with voltage output. The architecture in Fig. 1a is called the Kelvin-Varley divider and consists of two or more "string DACs" [25]. Since there are buffers between the first and second stages, the DAC of the second stage is not an input, and the resistors in this chain do not have to be of the same rating as the resistors in the other. However, all the resistors in each circuit must be equal to each other, otherwise the DAC will not be linear. Buffer amplifiers (BU) are biased and this can cause non-monotony in the DAC. In a simpler configuration of the Kelvin-Varley divider [25] (Fig. 1a), the "A" DAC is always "lower" (with a lower potential) than the "B" DAC, and an additional tap labeled "A" on the LSB line DAC is not required. Data decoding is performed by only two priority encoders. Instead of using a second resistor chain, you can use a binary DAC to generate the three lowest bits, as shown on Fig. 1b. It is very difficult to produce high-resolution R-2R ladder circuits. Therefore, it is quite common to make a highresolution DAC with a relay circuit for low-order bits, and a different structure [25] for two to five high-order bits.

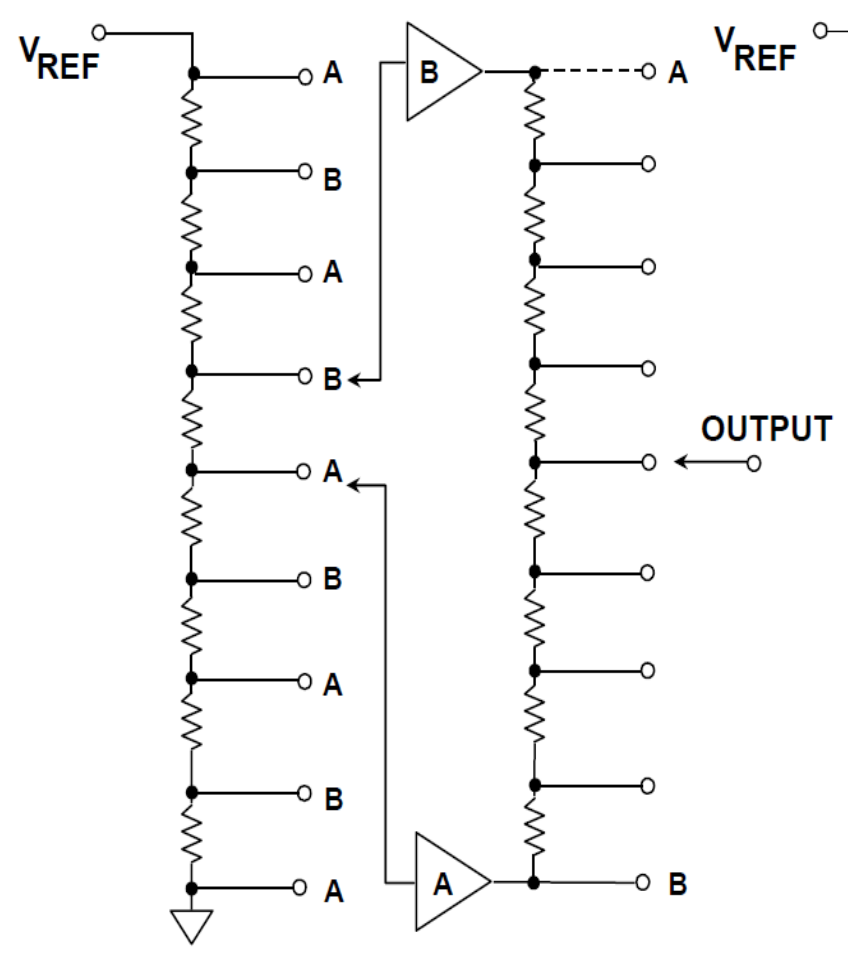

a)

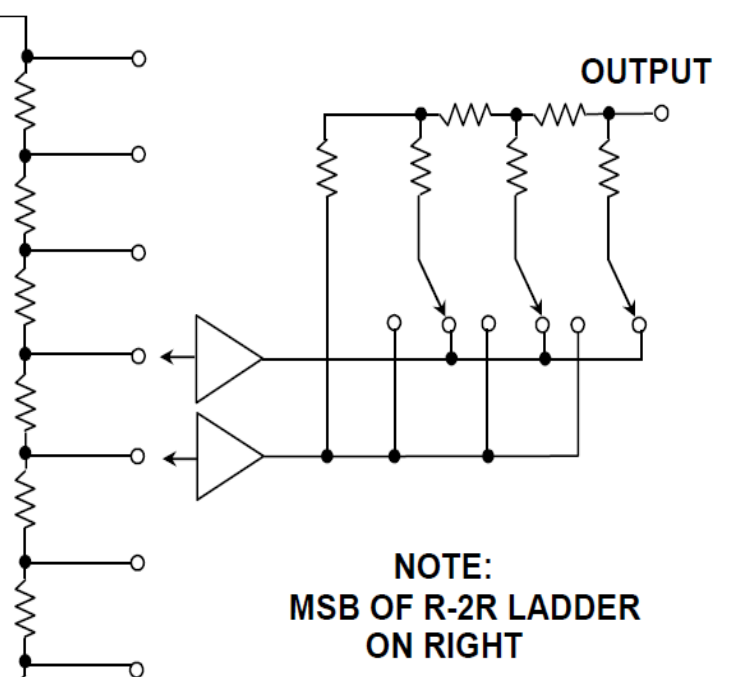

IF THE R-2R LADDER NETWORK IS MONOTONIC, THE WHOLE DAC IS MONOTONIC

b)

Fig. 1 Kelvin-Varley divider (a), Kelvin divider, and R-2R resistor matrix (b) [25]

Figure 2 shows an unbuffered version of the segmented-circuit DAC architecture. This version is more thought-out in concept (and, of course, can be 
manufactured based on CMOS processes that produce resistors and switches, so it can also be cheaper) [25].

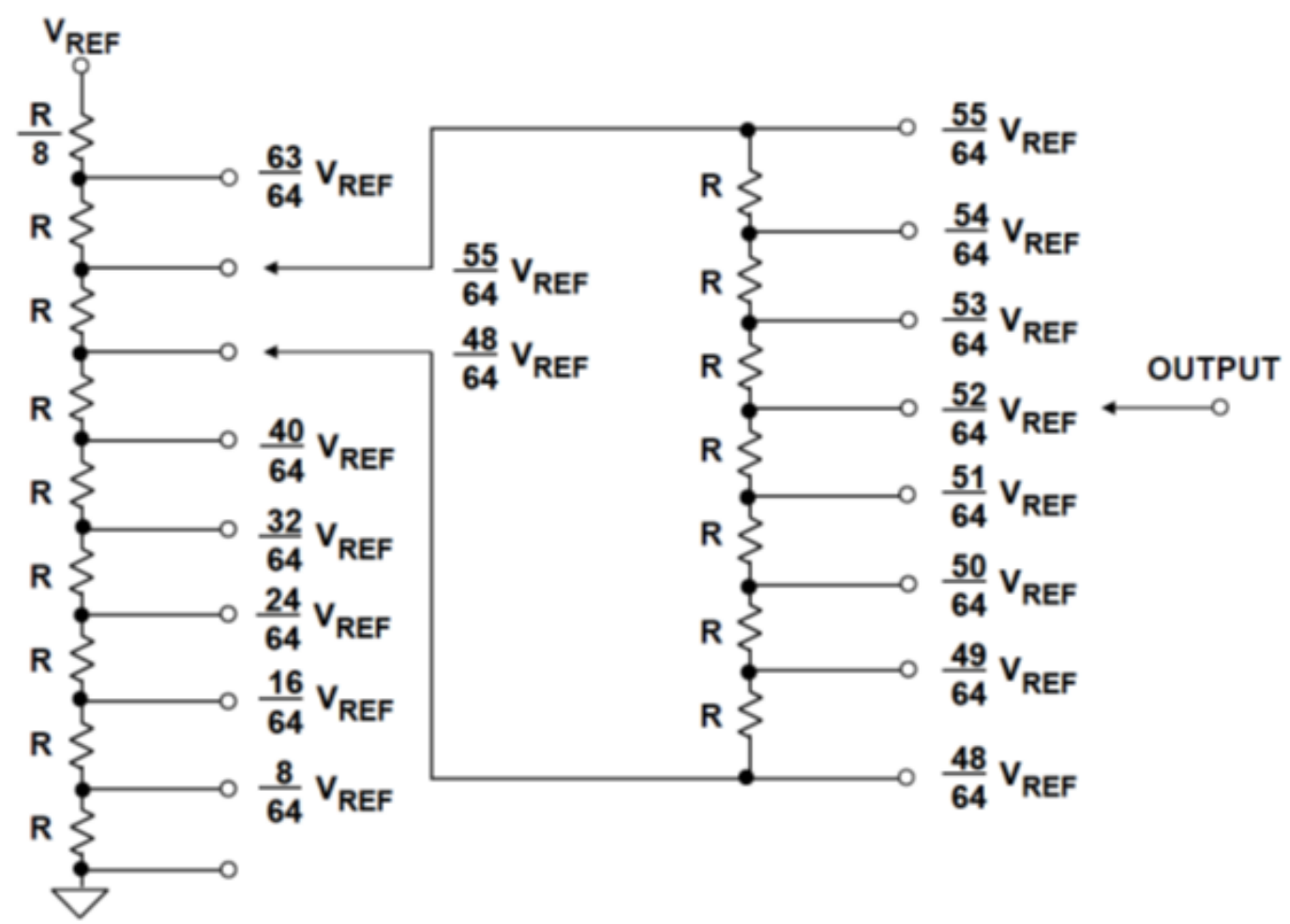

Fig. 2 Segmented unbuffered string DACs [25, 26]

Here (Fig. 2) the resistors in the two chains should be equal, except that the upper resistor in the MSB chain should be less ( $1 / 2 \mathrm{k} \Omega$ from the values of the others), and the LSB chain has resistors of $2 \mathrm{k} \Omega-1 \mathrm{k} \Omega$, but not $2 \mathrm{k} \Omega[25,26]$.

\section{Digital potentiometers}

$\mathrm{DP}$ is an adjustment element in ARCF and allow performing about 50 thousand adjustments before failure [29]. Previously, the ARCF used mechanical potentiometers (MP), which have, at best, several thousand adjustments. Since the MP is subject to mechanical wear, they lose to the DP in terms of reliability [29].

Figure 3 present the internal structure of the DP [29-30].

The DP of Analog Devices range offers excellent performance over a wide range of industrial temperatures. These compact devices, sometimes called digital pot, RDAC, or digiPOT, can be used to calibrate system errors or dynamically adjust parameters. DPs, such as the AD5123 and AD5143 (Fig. 4) [33] have nonvolatile memory, 128 / 256 adjustment positions, a small tolerance deviation from the nominal resistance, and a low temperature coefficient, which simplifies the creation of applications with an open feedback loop or applications where the tolerance values need to be matched. 


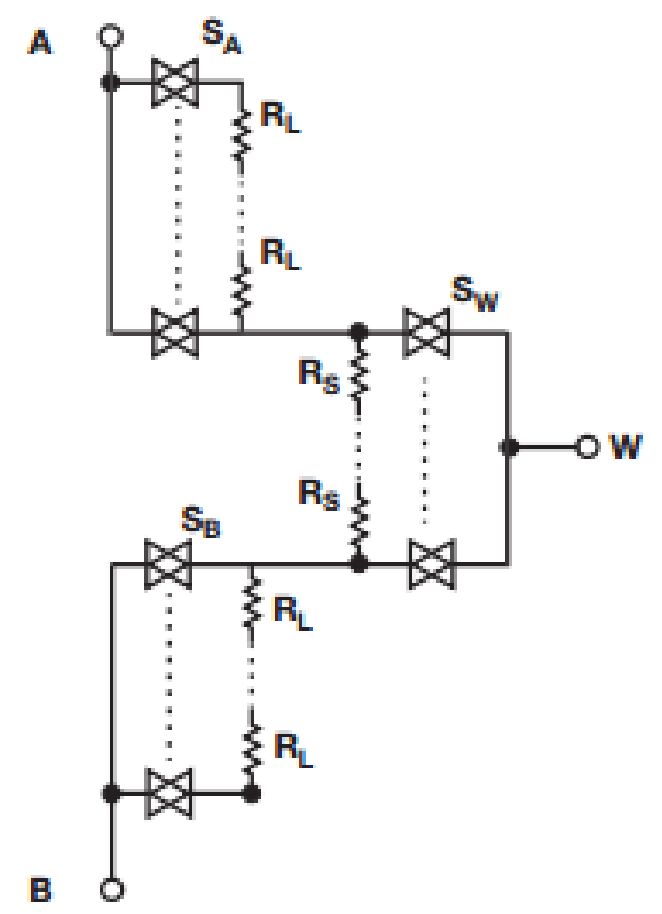

Fig. 3 Internal structure of DP [30]

DPs of ADI digiPOT+ AD5270/AD5271/AD5272/AD5274 are singlechannel, contain 1024-/256-position resistors with digital control, through-pass resistor tolerance error of less than $1 \%$, and programmable memory [32].

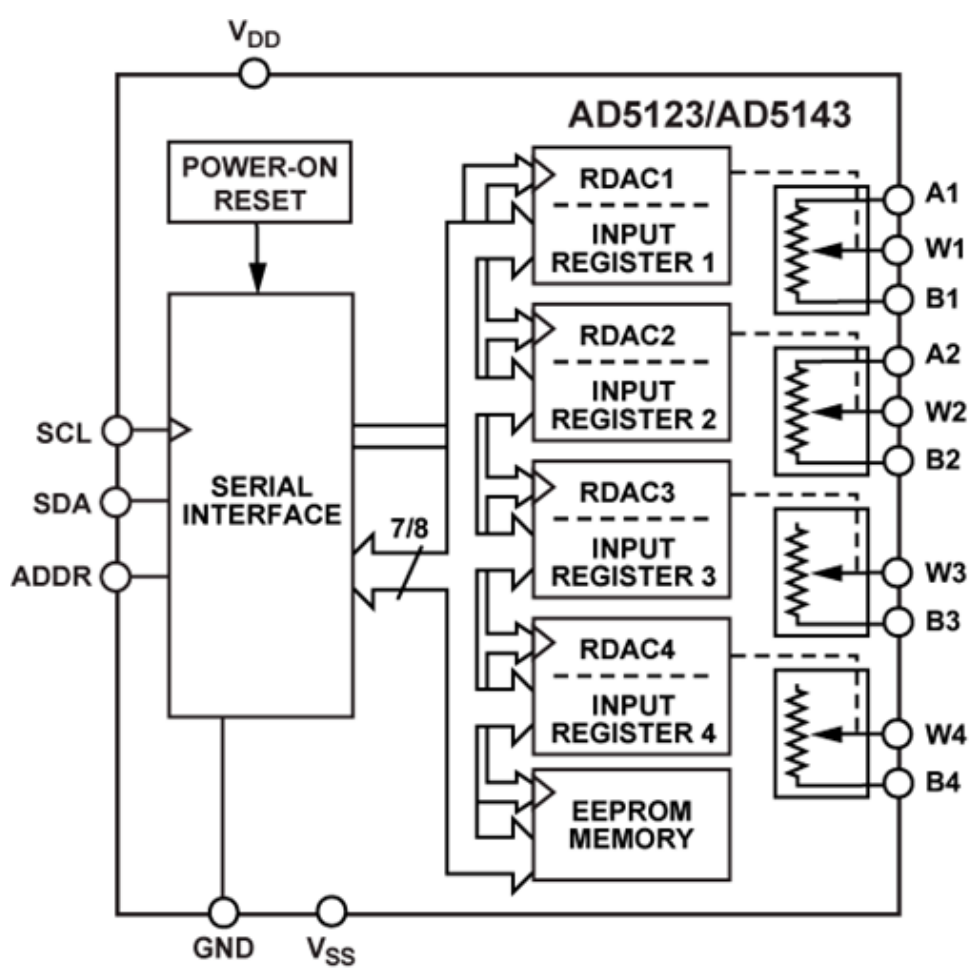

Fig. 4 Functional block diagram of the AD5123 and AD5143 [32] 
Figure 5 shows three examples of DPs that are manufactured in small packages [33].

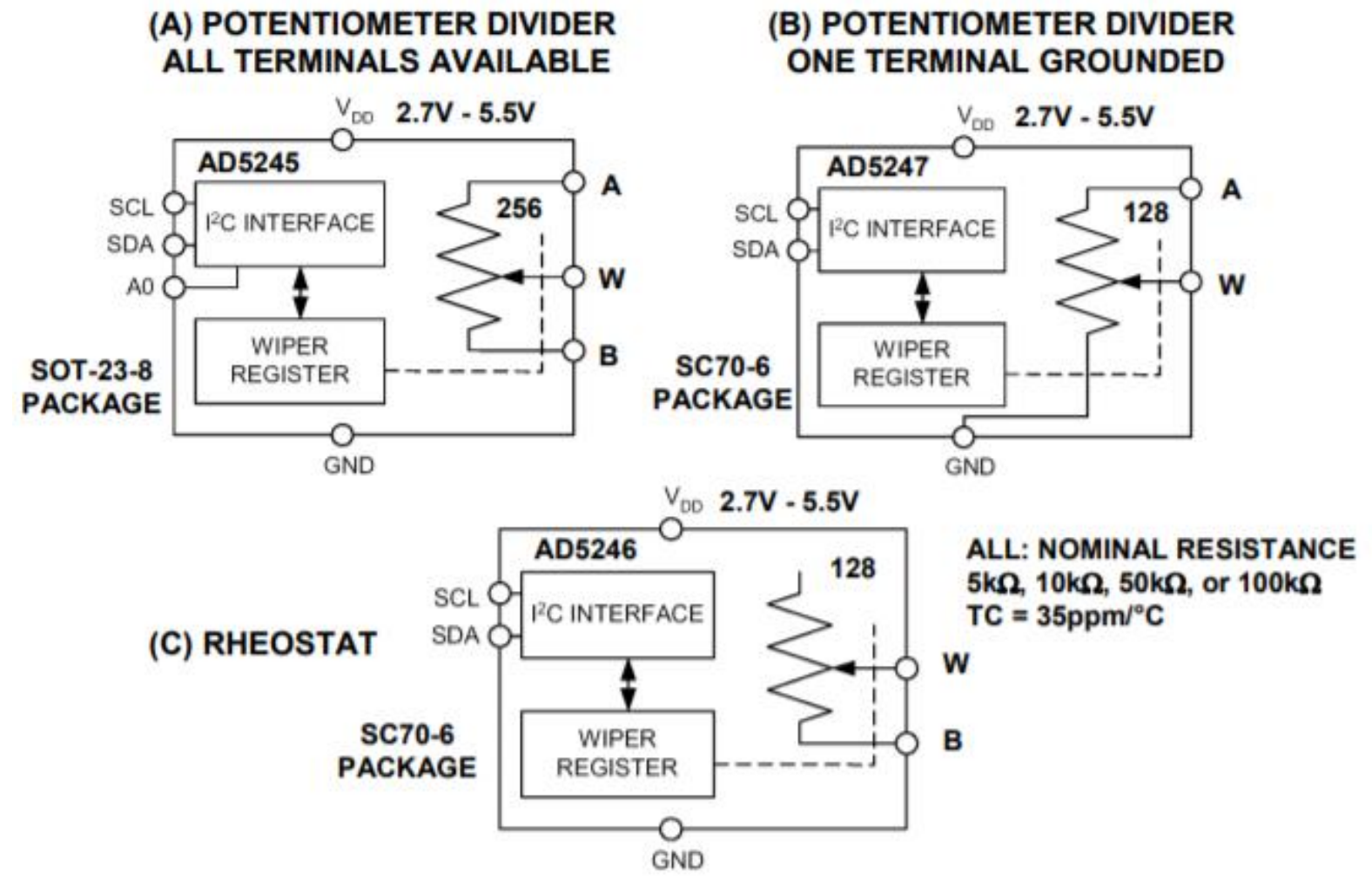

Fig. 5 The DP usage examples [33]

On Fig. 6 presented the options for using the DP in a low-pass filter and a band-pass filter, inverting amplifiers, and voltage regulators [37-38].

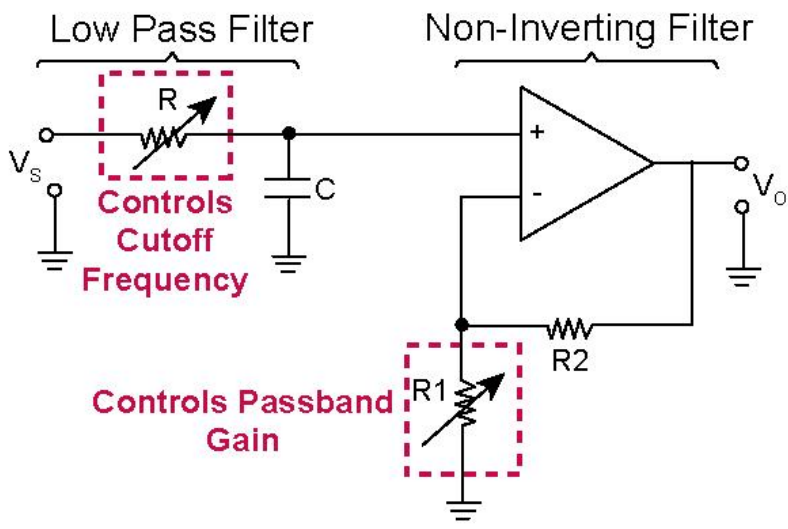

a)

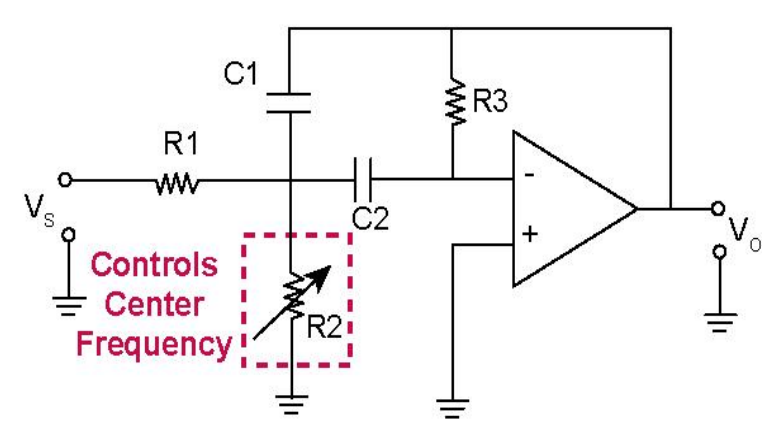

b) 


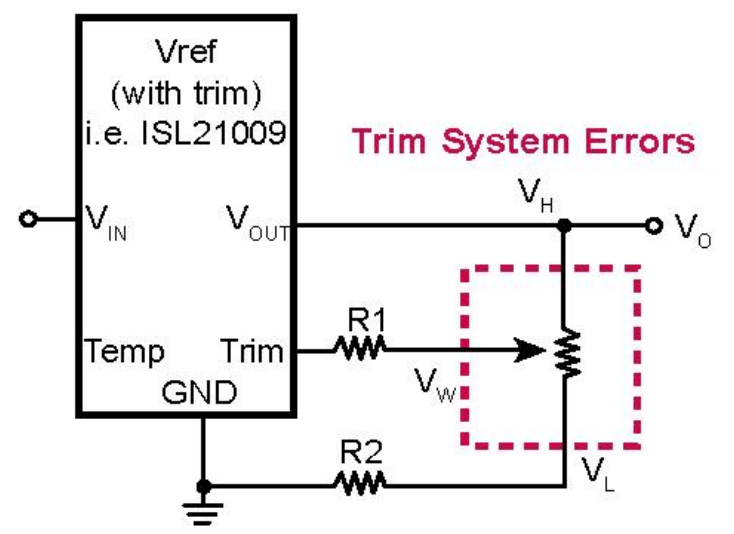

c)

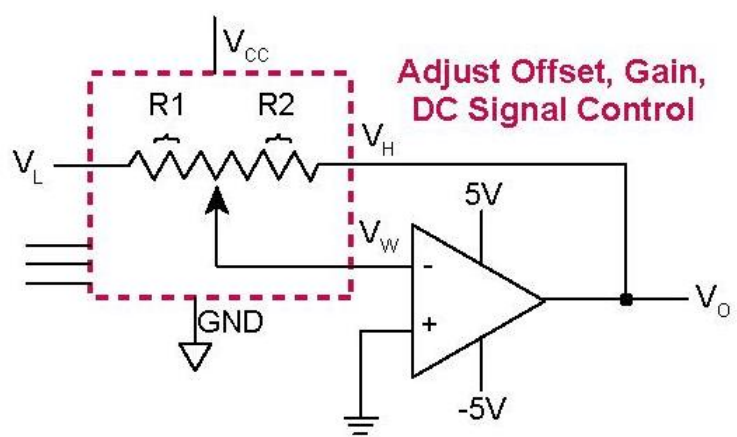

d)

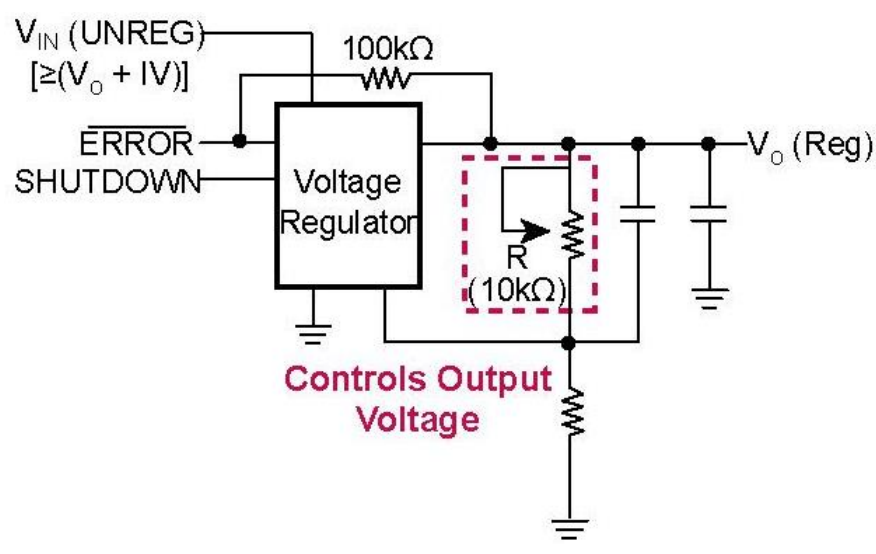

e)

Fig. 6 Programmable low-pass filter and gain unit (a), programmable band-pass filter (b), reference voltage source (c), programmable inverting amplifier (d), programmable voltage regulator (e).

\section{Conclusion}

The attention of developers of analog devices is drawn to the fact that today the DP and DAC are effectively used as controlled signal dividers, as well as elements of the adjustment of ARCF. Examples include DP switching circuits in the low-pass filter and band-pass filter, inverting amplifiers and voltage regulators.

The research has been carried out at the expense of the Grant of the Russian Science Foundation (project No. 18-79-10109). 


\section{References}

1. R. P. Sallen and E. L. Key, "A practical method of designing RC active filters," in IRE Transactions on Circuit Theory, vol. 2, no. 1, pp. 74-85, March 1955, doi: 10.1109/TCT.1955.6500159.

2. "Analysis of the Sallen-Key Architecture (Rev. B) - Texas Instruments," September 2002. [Online]. Available: https://www.ti.com/lit/an/sloa024b/sloa024b.pdf?ts=1599366712324\&ref_url $=$ https $\% 253 \mathrm{~A} \% 252 \mathrm{~F} \% 252 \mathrm{Fwww}$.google.com\%252F

3. S. A. Pactitis, Active Filters: Theory and Design, CRC Press, 2018, 288 p.

4. H. Huang, K. Chen, J. Xie, M. Lee, H. Hong and K. Cheng, "Gm-C filter with automatic calibration scheme," 2016 IEEE 19th International Symposium on Design and Diagnostics of Electronic Circuits \& Systems (DDECS), Kosice, Slovakia, 2016, pp. 1-4, doi: 10.1109/DDECS.2016.7482471.

5. A. Vasilopoulos, G. Vitzilaios, G. Theodoratos and Y. Papananos, "A LowPower Wideband Reconfigurable Integrated Active-RC Filter With $73 \mathrm{~dB}$ SFDR," in IEEE Journal of Solid-State Circuits, vol. 41, no. 9, pp. 1997-2008, Sept. 2006, doi: 10.1109/JSSC.2006.880616.

6. S. M. Newton and P. R. Kinget, "A 4th-order analog continuous-time filter designed using standard cells and automatic digital logic design tools," 2016 IEEE International Symposium on Circuits and Systems (ISCAS), Montreal, QC, Canada, 2016, pp. 297-300, doi: 10.1109/ISCAS.2016.7527229.

7. M. Anderson et al., "A 4.75-34.75 MHz digitally tunable active-RC LPF for $>60 \mathrm{~dB}$ mean RX IRR in 65nm CMOS," 2012 Proceedings of the ESSCIRC (ESSCIRC), Bordeaux, France, 2012, pp. 470-473, doi: 10.1109/ESSCIRC.2012.6341357.

8. N. Sabatino, G. Minoia, M. Roche, D. Baldi, E. Temporiti and A. Mazzanti, "A 5th order gm-C low-pass filter with $\pm 3 \%$ cut-off frequency accuracy and 220MHz to 3.3GHz tuning-range in 28nm LP CMOS," ESSCIRC 2014 - 40th European Solid State Circuits Conference (ESSCIRC), Venice Lido, Italy, 2014, pp. 351-354, doi: 10.1109/ESSCIRC.2014.6942094.

9. "Programmable Low-Pass Filter Design Using A Digital Pot And FilterLab, Electronic Design," September 2000. [Online]. Available: http://electronicdesign.com/components/programmable-low-pass-filterdesign-using-digital-pot-and-filterlab 
10. V. A. Simon, V. A. Gerasimov, D. K. Kostrin, L. M. Selivanov, A. A. Ukhov, "A notch filter with configurable parameters", Izvestiya SPbGETU LETI, 2017, no. 5, pp. 3-9. (in Russian).

11. S. A. Bukashkin, V. P. Vlasov, B. F. Zmiy, "Handbook of calculation and design of ARC-schemes", Moscow, Radio and Communication publishing, 1984, 368 p. (in Russian).

12. T. Yu. Kutsko, "Calculation of bandpass filters", Leningrad, Energiya publishing, 1965, 192 p. (in Russian).

13. S. G. Krutchinsky, N. N. Prokopenko, P. S. Budyakov, "Active bandpass filters of the RF and microwave bands: Basic structures based on current amplifiers", Lap Lambert Academic Publishing GmbH KG, 2013, 84 p. (in Russian).

14. U. Titze, K. Schenk, "Semiconductor circuitry: A reference guide," Moscow, Mir publishing, 1982, 512 p. (in Russian).

15. P. Horowitz, W. Hill, "The Art of Electronics," Cambridge University Press, 2015, $1220 \mathrm{p}$.

16. L. P. Huelsman, P. E. Allen, "Introduction to the theory and design of active filters", McGraw-Hill, 1980, 429 p.

17. V. I. Kapustyan, "Active high-order RC filters", Moscow, Radio and Communication publishing, 1985, 248 p. (in Russian).

18. G. S. Moshytz, P. Horn, "Active Filter Design Handbook", John Wiley \& Sons, New York, 1981.

19. H. Lam, "Analog and Digital Filters: Design and Realization," Engleewood Cliffs, NJ: Prentice Hall, 1979.

20. T. F. Schubert, E. M. Kim, "Fundamentals of Electronics, Book 3. Active Filters and Amplifier Frequency Response," Morgan \& Claypool Publishers, 2014, 924 p.

21. H. G. Dimopoulos, "Analog Electronic Filters: Theory, Design and Synthesis," Springer Science+Business Media New York, 2015, 577 p.

22. J. Piskorowski, R. Kaszyski, M. Anda, A. Sarmiento-Reyes, "A new approach to the design of post-DAC filters," 19th IMEKO World Congress 2009. Vol.1.

23. "Equalizing techniques flatten DAC frequency response," Maxim Integrated Products, Inc. August 2012. [Online]. Available: https://www.maximintegrated.com/en/design/technical-documents/appnotes/3/3853.html 
24. R. Bogner, A. Konstantinidis, "Introduction to digital filtering," Moscow, Mir publishing, 1976, 478 p. (in Russian).

25. W. Kester, "Basic DAC Architectures III: Segmented DACs. January, 2009. [Online]. Available: https://www.analog.com/media/cn/trainingseminars/tutorials/MT-016.pdf

26. D. Dempsey, C. Gorman, "Digital-to-analog converter," U.S. Patent 5969657, October 1999.

27. "MCP413X/415X/423X/425X, 7/8-Bit Single/Dual SPI Digital POT with Volatile Memory." February, 2008. [Online]. Available: https://ru.mouser.com/datasheet/2/268/22060a-53835.pdf

28. G. J. Zhou, J. Cheng, L. J. Qi, "Realization of Programmable Analog Circuits with Digital Potentiometer, Applied Mechanics and Materials," 2015. vol. 716-717, pp. 1248-1251. DOI: 10.4028/www.scientific.net/AMM.716717.1248 .

29. A. J. Lopez-Martin and A. Carlosena, "Low-cost analog interface circuit for resistive bridge sensors," 2013 13th International Symposium on Communications and Information Technologies (ISCIT), Surat Thani, Thailand, 2013, pp. 338-341, doi: 10.1109/ISCIT.2013.6645877.

30. "A Digitally Controllable Lowpass Filter Using a Digital Potentiometer." March, 2004. [Online]. Available: https://pdfserv.maximintegrated.com/en/an/AN3077.pdf

31. "Platan Electronic Components \# 6, Technical Documentation Library," Special Issue of Platan Magazine. [Online]. Available: https://www.platan.ru/docs/library/maxim1.pdf (in Russian).

32. D. Rice, J. Creech, "Digital Potentiometers vs. Mechanical Potentiometers: Important Design Considerations to Maximize System Performance.” 2015. [Online]. Available: https://www.analog.com/ru/technical-articles/digitalpotentiometers-vs-mechanical-potentiometers.html

33. "Quad Channel, 128-/256-Position, I2C, Nonvolatile Digital Potentiometer AD5123/AD5143." 2016. [Online]. Available: https://www.analog.com/media/en/technical-documentation/datasheets/AD5123_5143.pdf

34. "Digital potentiometers." 2020. [Online]. Available: https://www.analog.com/ru/products/digital-to-analog-converters/digitalpotentiometers.html

35. "MT-091 TUTORIAL". January 2009. [Online]. Available: https://www.analog.com/media/en/training-seminars/tutorials/MT-091.pdf 
36. D. Yu. Denisenko, Y. I. Ivanov, N. N. Prokopenko, N. A. Dmitrienko, "Digital Potentiometers in the Tasks of Settings Precision Analog RC-filters Taking into Account the Tolerances for Passive Components," 2017 18th International Conference of Young Specialists on Micro/Nanotechnologies and Electron Devices (EDM), Erlagol, 2017, pp. 205-210, doi: 10.1109/EDM.2017.7981741.

37. "Intersil selection guide digital, Largest Selection of DCPs, (Digitally Controlled Potentiometers)." December 2010. [Online]. Available: https://s1.dtsheet.com/store/data/000165770.pdf?key=9b35ff5f72e97cd16d15 $254 \mathrm{~d} 06581342 \& \mathrm{r}=1$

38. C. Wojslaw, "Application Note AN133." December 2018. [Online]. Available: http://pdf.datasheetcatalog.com/datasheet/Xicor/mXyqxtx.pdf 